ARTICLE

\title{
Enantioselective access to chiral aliphatic amines and alcohols via Ni-catalyzed hydroalkylations
}

Shan Wang ${ }^{1}$, Jian-Xin Zhang ${ }^{1}$, Tian-Yi Zhang ${ }^{1}$, Huan Meng ${ }^{1}$, Bi-Hong Chen ${ }^{1} \&$ Wei Shu (i) ${ }^{1 凶}$

Chiral aliphatic amine and alcohol derivatives are ubiquitous in pharmaceuticals, pesticides, natural products and fine chemicals, yet difficult to access due to the challenge to differentiate between the spatially and electronically similar alkyl groups. Herein, we report a nickel-catalyzed enantioselective hydroalkylation of acyl enamines and enol esters with alkyl halides to afford enantioenriched $\alpha$-branched aliphatic acyl amines and esters in good yields with excellent levels of enantioselectivity. The operationally simple protocol provides a straightforward access to chiral secondary alkyl-substituted amine and secondary alkyl-substituted alcohol derivatives from simple starting materials with great functional group tolerance.

\footnotetext{
${ }^{1}$ Shenzhen Grubbs Institute and Department of Chemistry, Guangdong Provincial Key Laboratory of Catalysis, Southern University of Science and Technology, Shenzhen 518055, China. ${ }^{凶}$ email: shuw@sustech.edu.cn
} 
C hiral aliphatic amines and alcohols are widespread substructures in pharmaceutical molecules, natural products and organic materials, and serve as common chiral building blocks for other functional groups and value-added molecule synthesis ${ }^{1-3}$. Additionally, over half of small-molecule drugs are the derivatives of chiral aliphatic amines and alcohols among the top 200 best-selling drugs (Fig. 1a) ${ }^{4}$. Thus, the enantioselective synthesis of pure aliphatic amines and alcohols has been recognized as a long-term interest in chemistry community. Over the past decades, significant progress has been made in this field enabled by enantioselective $\mathrm{C}-\mathrm{H}$ amination/ oxygenation $^{5-8}$, addition of alkyl organometallic reagents to imines or aldehydes ${ }^{9-13}$, and hydrogenation of imines, enamines, ketones, or enol esters ${ }^{14-19}$. However, chiral catalysts have difficulty in identifying different faces of prochiral centers bearing two alkyl groups with similar steric and electronic properties ${ }^{20}$. Thus, these methods are typically applied to build chiral aliphatic amines and alcohols with the stereogenic center adjacent to aryl or carbonyl groups (Fig. 1b) $)^{14,21-24}$. To control the enantioselectivity of asymmetric reactions for regular secondary alkylsubstituted amines and alcohols still remains a formidable challenge. In 2020, Zhou group reported a breakthrough in Ircatalyzed asymmetric hydrogenation of dialkyl ketones to afford chiral aliphatic alcohols with good enantioselectivity enabled by a rationally designed bulky PNP ligand ${ }^{25}$. Buchwald developed a seminal work on $\mathrm{Cu}-\mathrm{H}$-catalyzed hydroamination of internal alkenes to achieve chiral dialkyl amines ${ }^{26,27}$. In 2016, Fu group reported a pioneer work on $\mathrm{Ni}-\mathrm{H}$-catalyzed racemic hydrofunctionalizations of alkenes with aryl or alkyl halides ${ }^{28}$, which have become a promising alternative for traditional asymmetric $\mathrm{C}-\mathrm{C}$ cross-coupling reaction to construct saturated stereogenic carbon centers ${ }^{28-35}$. The use of readily available and bench-stable alkenes as a masked nucleophile in the presence of silane circumvents the use of stoichiometric and often sensitive organometallic reagents, which usually require time-consuming preformation $^{36,37}$. The abundance of alkene as well as the mild conditions significantly enhanced the scope and functional group tolerance of this strategy ${ }^{38-41}$. Fu group reported the seminal work on the anti-Markovnikov hydroalkylation of alkenes with activated secondary alkyl halides to build a stereogenic center originating from alkyl halides ${ }^{42-45}$. The use of unactivated alkyl halides to build stereogenic center originating from alkenes remains elusive due to the reversible $\mathrm{Ni}-\mathrm{H}$ insertion onto alkenes and the propensity of chain-walking ${ }^{46,47}$. Recently, our group developed the Ni-H-catalyzed hydroalkylation of acrylates via anti-Markovnikov hydrometalation, giving the enantioenriched a-tertiary amides by forging a stereogenic center originating from acrylates $^{48}$. In 2021, Hu group reported a hydroalkylation of vinyl boronates to give chiral secondary alkyl boronates enabled by the anchoring effect of boron ${ }^{49}$. These examples showcased the feasibility of building a stereogenic carbon center originating from alkenes via Ni-catalyzed hydroarylation ${ }^{36-38}$ and hydroalkylation $^{48-51}$ of alkenes.

As part of our continuous interest in the enantioselective hydrofunctionalizations of alkenes, we envisioned the use of alkene adjacent to nitrogen or oxygen to undergo enantioselective hydroalkylation would furnish enantioenriched secondary aliphatic amine and alcohol derivatives (Fig. 1c). Here, we report the $\mathrm{Ni}-\mathrm{H}$-catalyzed regio- and enantioselective hydroalkylation of acyl enamines and enol esters with alkyl iodides to forge a stereogenic carbon center next to nitrogen or oxygen originating from alkenes in high enantioselectivity, providing a unified protocol for rapid access to chiral secondary alkyl-substituted amine and alcohol derivatives which are difficult to access otherwise $\mathrm{o}^{50-52}$.

\section{Results}

Reaction optimization. To test the feasibility of the reaction, we set out to identify the reaction parameters using acyl enamine 1a with 1-iodo-3-phenylpropane $\mathbf{2 a}$ as substrate in the presence of silane. (Table 1 and Tables S1-13; for more details on the condition optimization, please see the Supplementary information). First, a wide range of chiral ligands were tested for this reaction using $\mathrm{NiBr}_{2}$.glyme $(10 \mathrm{~mol} \%)$ as the nickel catalyst precursor, trimethoxysilane (TMS) as hydride source, and potassium phosphate monohydrate as base in diethyl ether at room temperature (Table 1, entries 1-9 and Table S1). When pyridineoxazolidine ligand (L1 or L2) was used, the desired hydroalkylation product 3 a was obtained in $54 \%$ and $29 \%$ yields with low

a Representative molecules containing chiral dialkyl amines and alcohols

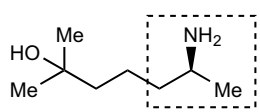

Heptaminol

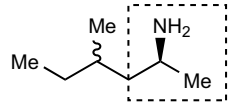

Forthane

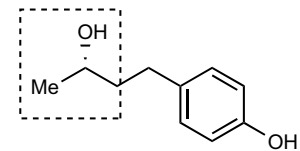

Rhododendrol

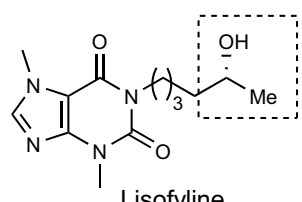

Lisofyline

b Representative ways to access chiral dialkyl amines and alcohols

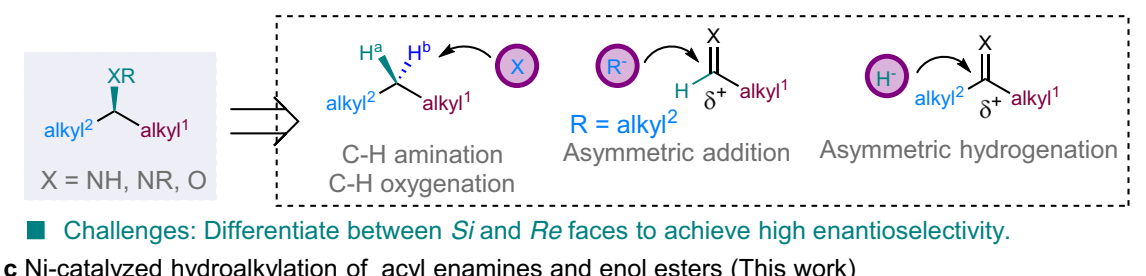

c Ni-catalyzed hydroalkylation of acyl enamines and enol esters (This work)

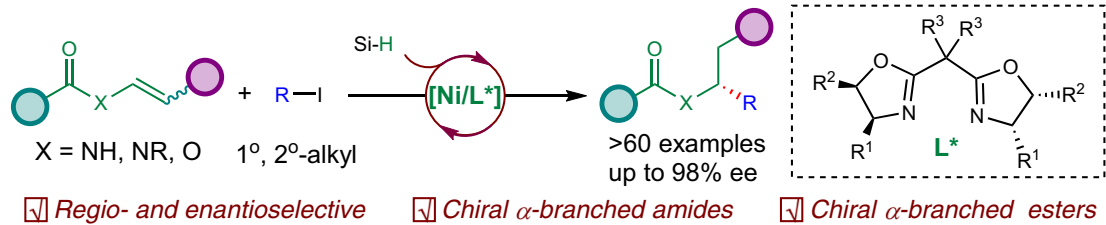

Fig. 1 Impetus for the development of the reaction. a Representative molecules containing chiral secondary alkyl-substituted amines and alcohols. b Representative ways to access chiral secondary alkyl-substituted amines and alcohols. c Ni-catalyzed hydroalkylation of acyl enamines and enol esters. 
Table 1 Condition evaluation of the reaction.

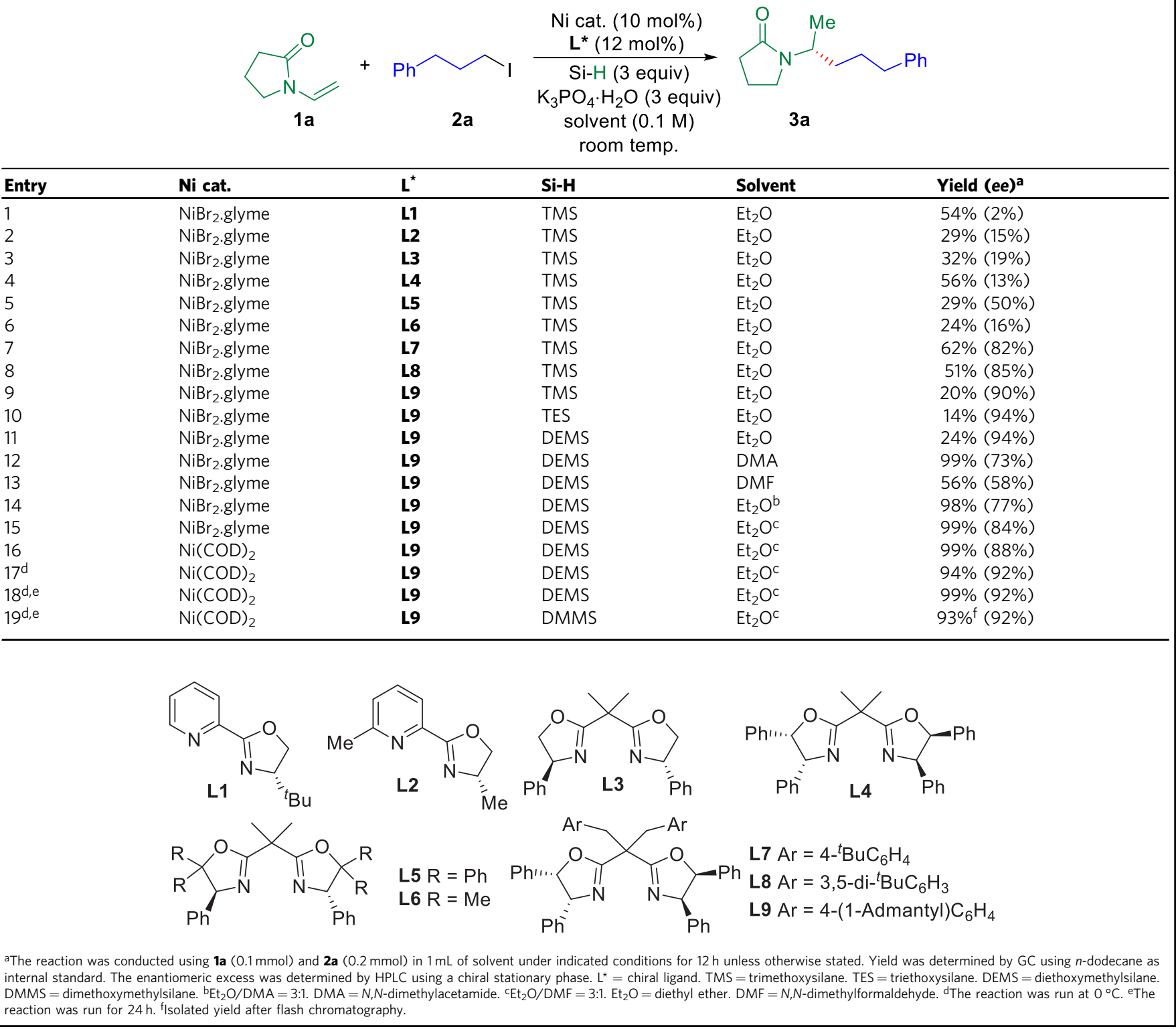

enantiomeric excesses (2\% and 15\%), respectively (Table 1, entries 1 and 2). Ph-Box ligands (L3-L6) could catalyze the reaction, giving $\mathbf{3 a}$ in low yields with low enantioselectivities (Table 1, entries 3-6). Increasing the steric hindrance at a-position to oxygen increased the enantioselectivity of $\mathbf{3 a}$ to $50 \%$ ee (Table 1, entries 5 and 6). Modifying the methyl group on L4 to bulkier groups significantly improved the enantioselectivity of 3a (Table 1, entries 7-9). The use of L9 delivered 3a in 20\% yield with $90 \%$ ee. Using diethoxymethylsilane (DEMS) as hydride source slightly increased the enantioselectivity of $3 \mathbf{a}$ to 94\% (Table 1, entry 11). Next, the solvent for the reaction was evaluated. The use of $\mathrm{N}, \mathrm{N}$-dimethylacetamide (DMA) or $N, N$-dimethylformaldehyde (DMF) dramatically increased the efficiency of the reaction, delivering $\mathbf{3 a}$ in up to $99 \%$ yield with diminished enantiomeric excess (Table 1, entries 12 and 13). The mixing of ether with DMA or DMF could increase the enantioselectivity of $\mathbf{3 a}$ without erasing the efficiency of the reaction
(Table 1, entries 14 and 15). Further optimization of the nickel precursor and reaction temperature improved the yield and enantioselectivity of 3a (Table 1, entries 16-18). The use of $\mathrm{Ni}$ $(\mathrm{COD})_{2} \quad(10 \mathrm{~mol} \%), \quad$ L9 (12 mol\%), dimethoxymethylsilane (DMMS) (3 equiv.) in $\mathrm{Et}_{2} \mathrm{O}$ and $\mathrm{DMF}$ (3:1) gave $3 \mathrm{a}$ in $93 \%$ yield with $92 \%$ ee (Table 1 , entry 19 ).

Substrate scope of dialkyl amides. With the optimized conditions in hand, we turned to evaluate the scope of this reaction. First, we tested different alkyl iodides with tertiary acyl enamine 1a (Fig. 2). Then, 4-phenylbutyliodide was converted to chiral amide $\mathbf{3 b}$ in $93 \%$ yield with $92 \%$ ee. 2 -Phenyl-1-iodoethane and a-branched alkyl iodides could be transformed into corresponding amine derivatives (3c and 3d) in $87 \%$ and $58 \%$ yields with $89 \%$ ee. Heterocyclic compounds, such as carbazoles, indoles, and thiophenes, worked well in the reaction, furnishing the regio- and 


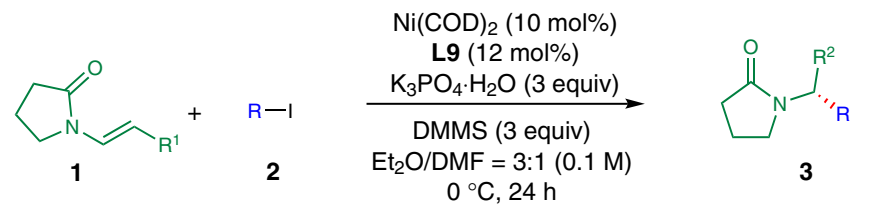

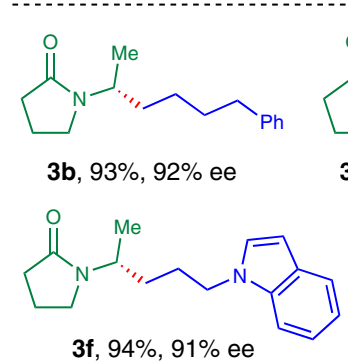

3f, $94 \%, 91 \%$ ee<smiles>CCOCCC[C@H](C)N1CCCC1=O</smiles>

$3 \mathbf{3 i}, 83 \%, 89 \%$ ee<smiles>C[C@H](CCCCCO[Si](c1ccccc1)(c1ccccc1)C(C)(C)C)N1CCCC1=O</smiles>

$31,85 \%, 74 \%$ ee<smiles>CC[C@H](CCCn1c2ccccc2c2ccccc21)N1CCCC1=O</smiles>

3o, $74 \%, 90 \%$ ee ${ }^{b}$ (from $(E)$-acyl enamine)

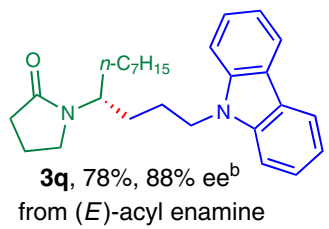<smiles></smiles>

$3 c, 87 \%, 89 \%$ ee

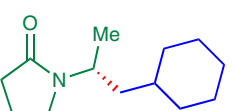

3d, $58 \%, 89 \%$ ee<smiles>C[C@H](CCCc1cccs1)N1CCCC1=O</smiles>

3g, $64 \%, 91 \%$ ee<smiles>COCCCC[C@H](C)N1CCCC1=O</smiles>

3j, $65 \%, 92 \%$ ee<smiles>O=C1CCCN1[CH]CCc1cccc(Cl)c1</smiles>

3m, 95\%, 88\% ee<smiles>C[C@H](CCCn1c2ccccc2c2ccccc21)N1CCCC1=O</smiles><smiles>[M]C(CCCN1C(=O)c2ccccc2C1=O)N1CCCC1=O</smiles>

$3 h, 83 \%, 91 \%$ ee<smiles>O=C1CCCN1[CH]CCOc1ccccc1</smiles>

3k, $56 \%, 89 \%$ ee<smiles>C[C@@H](Cc1ccccc1)N1CCCC1=O</smiles>

3n, $88 \%, 61 \%$ ee<smiles>CC[C@H](CCCn1c2ccccc2c2ccccc21)N1CCCC1=O</smiles>

3o, $80 \%, 81 \%$ ee from acyl enamine $(Z / E=10: 1)$

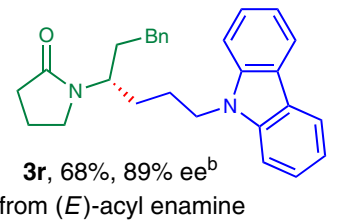<smiles>CCCCCCCCCn1c2ccccc2c2ccccc21</smiles>

3p, $76 \%, 88 \%$ ee from $(E)$-acyl enamine

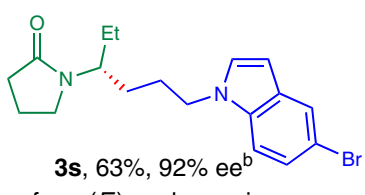

from $(E)$-acyl enamine

Fig. 2 Scope for alkyl iodides of tertiary acyl enamines and internal acyl enamines. For reaction conditions, see Table 1, entry 19 unless otherwise stated. aBenzyl bromide was used. 'The reaction was conducted using $1(0.2 \mathrm{mmol}), \mathbf{2}(0.6 \mathrm{mmol})$ at $45^{\circ} \mathrm{C}$ for $16 \mathrm{~h}$.

enantioselective hydroalkylation products $(\mathbf{3 e}-\mathbf{3 g})$ in $64-94 \%$ yields with $91 \%$ ee. Other functional groups, such as amides, esters, ethers were also compatible under the reaction conditions, delivering the desired chiral amine derivatives (3h-3k) in 56-83\% yields with $89-92 \%$ ee. Moreover, silylethers and arylchlorides were tolerated in the reaction, giving the desired products ( 31 and $3 \mathrm{~m}$ ) in $85 \%$ and $95 \%$ yields with $74 \%$ and $88 \%$ ee, leaving chemical handles for further elaboration. Benzyl bromide was successfully converted to corresponding amide $\mathbf{3 n}$ in $88 \%$ yield with moderate enantiomeric excess. Second, internal acyl enamines were examined. Internal acyl enamines with diverse substituents could be converted to corresponding hydroalkylated products in good yields with excellent enantioselectivities. Acyl (E)-1-propenamine reacted to give corresponding dialkyl amide 3o in $74 \%$ yield with $90 \%$ ee. Alternatively, acyl (Z)-1-propenamine gave 30 in $80 \%$ yield with $81 \%$ ee under the same conditions. Longer alkyl chain- and benzyl-substituted internal acyl enamines were all good substrates for this reaction, affording corresponding amine derivatives (3p-3r) in 68-78\% yields with $88-89 \%$ ee. Bromoindole containing alkyl iodide could be coupled with internal acyl enamine to deliver $3 \mathrm{~s}$ in $63 \%$ yield with $92 \%$ ee.
Next, the scope of secondary acyl enamines was tested (Fig. 3). A wide range of secondary acyl enamines were well-tolerated in this reaction, forming a myriad of enantioenriched amides in good efficiency with excellent levels of enantioselectivity in the presence of L41. Various aromatic amides were good substrates for this reaction $(\mathbf{4 a}-\mathbf{4 o})$. Electron-donating substituted aromatic acyl enamines could be converted to corresponding hydroalkylated products $(\mathbf{4 a}-\mathbf{4 f})$ in $68-90 \%$ yields with $90-95 \%$ ee. Electron-withdrawing substituents, such as trifluoromethyl, cyano, ester, fluoride, were well-tolerated under the reaction conditions, giving the desired products $(\mathbf{4 g}-\mathbf{4 j})$ in $74-89 \%$ yields with $93-96 \%$ ee. Fused aromatic and heteroaromatic acyl enamines, including naphthalene, furan, thiophene, and pyridine, were transformed into corresponding chiral amides $(\mathbf{4 k - 4 o})$ in $49-88 \%$ yields with $89-95 \%$ ee. The structure and absolute configuration of the product was determined by the X-ray diffraction analysis of $4 \mathbf{1}$. Aliphatic acyl enamines were also tested $(\mathbf{4 p}-\mathbf{4 v})$. Linear and $\alpha$-branched aliphatic acyl enamines with acidic $\alpha$-proton, such as methyl, $n$-propyl, isopropyl, cyclopropyl, cyclohexyl, were all good substrates for this hydroalkylation reaction, affording corresponding chiral amides (4p-4t) in 

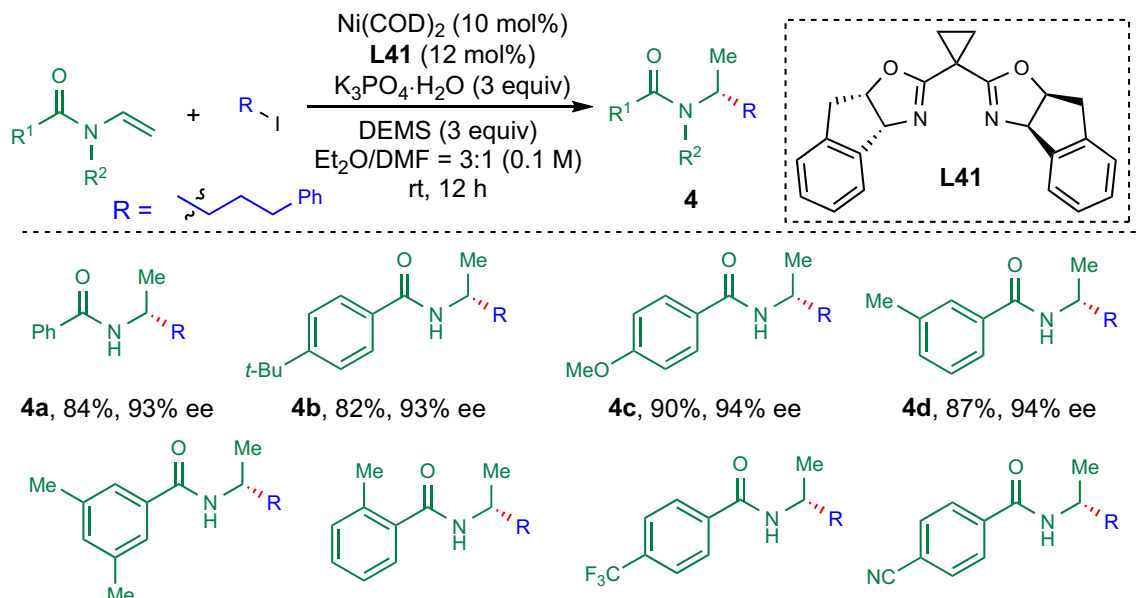

4 e, $79 \%, 95 \%$ ee

4f, $68 \%, 90 \%$ ee

4g, $88 \%, 95 \%$ ee

4h, $89 \%, 94 \%$ ee
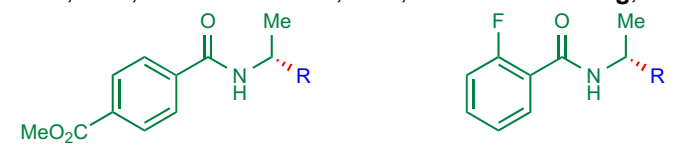

$4 \mathrm{j}, 82 \%, 93 \%$ ee

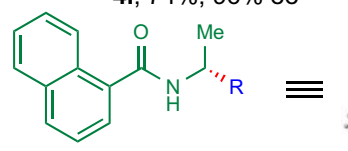

4I, $68 \%, 93 \%$ ee<smiles>[R]C(C)NC(=O)c1ccc(Cl)nc1</smiles>

4o, $49 \%, 89 \%$ ee<smiles>[R]C(C)NC(=O)C1CC1</smiles>

4s, $88 \%, 96 \%$ ee

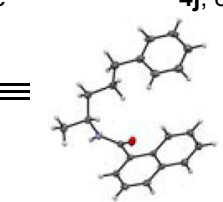<smiles>[R]C([2H])NC(C)=O</smiles>

4p, $68 \%, 93 \% \mathrm{ee}^{\mathrm{a}}$<smiles>[R]C(C)NC(=O)C1CCCCC1</smiles>

4t, $73 \%, 93 \%$ ee<smiles>[R]C(C)NC(=O)c1ccco1</smiles>

$4 \mathrm{~m}, 81 \%$, $95 \%$ ee<smiles>[R]C(C)NC(=O)C(=O)O</smiles>

4q, $51 \%, 93 \%$ ee<smiles>CCCCC(C)(C)C(=O)NCCCCC(C)(C)C</smiles>

$4 u, 84 \%, 92 \%$ ee<smiles>[R]C(C)NC(=O)c1ccc2ccccc2c1</smiles>

$4 \mathbf{k}, 88 \%, 95 \%$ ee<smiles>CCCCCC(=O)NC(=O)c1cccs1</smiles>

4n, $68 \%$, 95\% ee<smiles>[R]C(C)NC(=O)C(C)[NH3+]</smiles>

$4 r, 68 \%, 90 \% e^{a}$<smiles>[R9]C(C)N(CC)C(C)=O</smiles>

$4 \mathbf{v}, 79 \%, 80 \% \mathrm{ee}^{\mathrm{b}}$

Fig. 3 Scope for secondary acyl enamines. The reaction was run on $0.2 \mathrm{mmol}$ of acyl enamine and $0.4 \mathrm{mmol}$ of alkyl iodide using DEMS (0.6 mmol) under indicated conditions unless otherwise stated. ${ }^{a}$ DMMS was used instead of DEMS. b ${ }^{b} \mathbf{4}$ was used as the ligand.

$51-88 \%$ yields with $90-96 \%$ ee. a-Tertiary alkyl acyl enamines reacted to give $\mathbf{4 u}$ in $84 \%$ yield with $92 \%$ ee. N-methyl aliphatic acyl enamine was converted to $\mathbf{4 v}$ in $79 \%$ yield with $80 \%$ ee.

Then the scope for alkyl iodide for secondary acyl enamines was examined (Fig. 4). Secondary acyl enamines gave better enantioselectivity using the analogue ligand L41. Then, 5-(2Iodoethyl)-2,3-dihydrobenzofuran was successfully hydroalkylated to give $\mathbf{5 a}$ in $84 \%$ yield with $96 \%$ ee. The structure and absolute configuration of $\mathbf{5 a}$ was further determined by the X-ray diffraction analysis. It is noteworthy that the minimal structurally different secondary alkyl-substituted amine derivative $\mathbf{5 b}$ was obtained by this protocol in $65 \%$ yield with $94 \%$ ee. Other 1iodoalkanes were also successfully converted to corresponding amine derivatives $(\mathbf{5 c}-\mathbf{5 e})$ in $63-80 \%$ yields with $93-98 \%$ ee. Chiral aminoalcohol and aminoester derivatives $(\mathbf{5} \mathbf{f}-\mathbf{5 h})$ were obtained in $62-72 \%$ yields with $92-94 \%$ ee. Cyclic secondary alkyl iodides were also reactive under the reaction conditions to furnish the desired products $5 \mathbf{i}$ and $5 \mathbf{j}$ in $66 \%$ and $61 \%$ yields with $98 \%$ and $92 \% e e$. To demonstrate the robustness and usefulness of this protocol, we applied this reaction to late-stage functionalization of natural product derivatives. (+)-Borneol, L-menthol, cholesterol, and vitamin E derived acyl enamines could be transformed to give corresponding chiral amides (5k-5n) in $45-87 \%$ yields with $97: 3$ to $98: 2 \mathrm{dr}$.
Substrate scope of dialkyl esters. Next, enol esters were tested under the reaction conditions. To our delight, various enol esters could be tolerated and a wide range of chiral aliphatic alcohol derivatives were obtained in high enantioselectivity, which are difficult to access otherwise (Fig. 5). Aromatic or aliphatic acidderived enol esters were all good substrates for this reaction, furnishing corresponding chiral esters (6a-6c) in $53-73 \%$ yields with $80-92 \%$ ee. Alkyl iodides containing ester, ether, thiophene, amide could be transformed to corresponding chiral alcohol derivatives $(\mathbf{6 d - 6 g})$ in $51-80 \%$ yields with $90-95 \%$ ee. Notably, 1 -iodohexane and 1-iodobutane were successfully involved in the reaction to give octan-2-ol (6h) and hexan-2-ol (6i) derivatives in $77 \%$ and $54 \%$ yields with $90 \%$ and $96 \%$ ee, respectively. Secondary alkyl iodide was tolerated in the reaction, furnishing the desired product $(\mathbf{6 j})$ in synthetic useful yields with $97 \%$ ee. Moreover, internal enol esters were well-tolerated in the reaction. Long-chain alkyl-substituted internal enol esters were successfully converted to corresponding chiral esters $(6 \mathbf{k}-6 \mathbf{m})$ in $58-70 \%$ yields with $91-94 \%$ ee. Chloro-containing alkyl-substituted internal enol ester underwent the desired hydroalkylation reaction to give 6 n in $68 \%$ yield with $94 \%$ ee. The absolute configuration of the chiral ester was confirmed to be $R$ by comparison to literature ${ }^{53-55}$. Furthermore, literature procedures proved unprotected chiral aliphatic amines and 


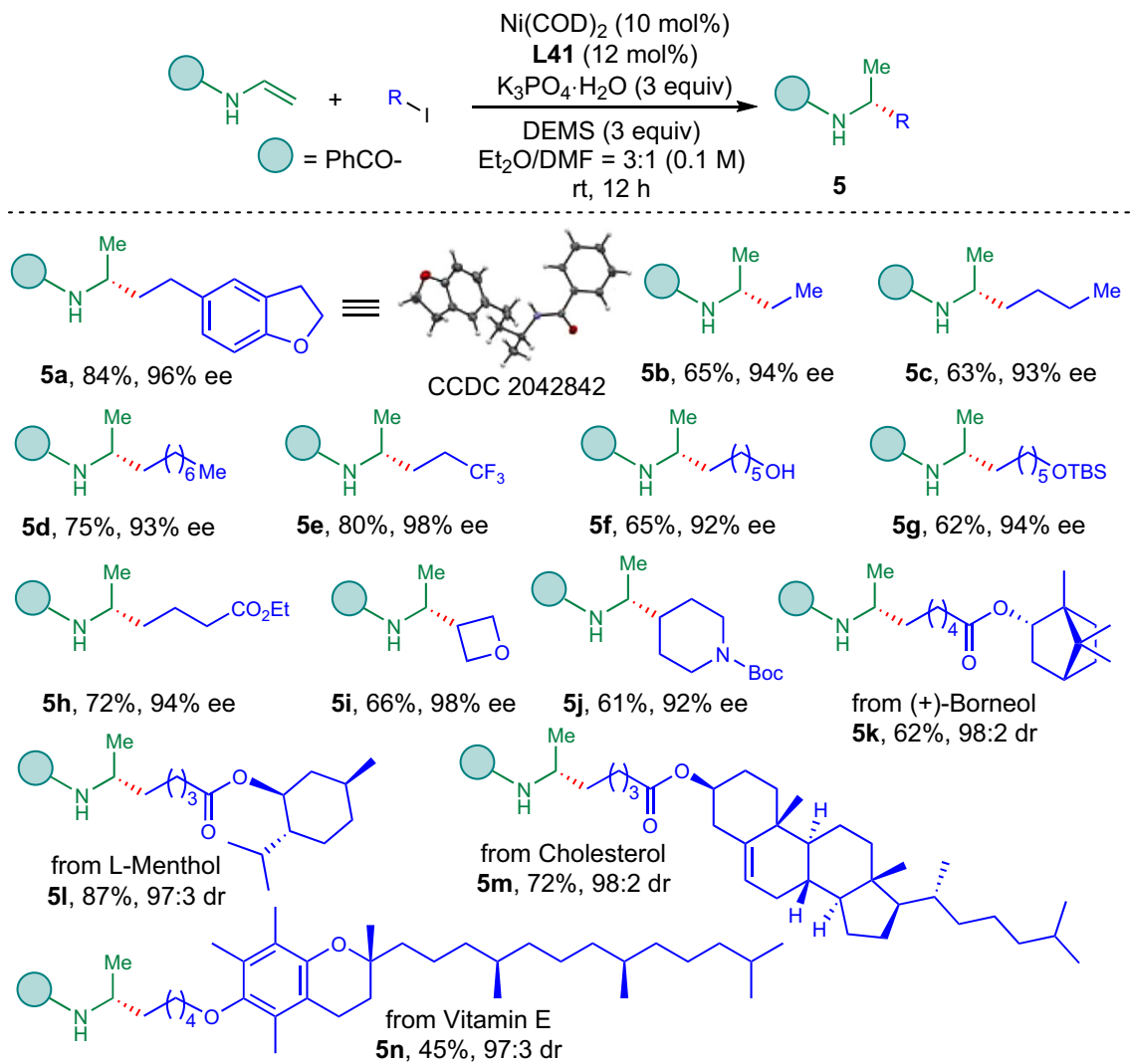

Fig. 4 Scope for alkyl iodides with secondary acyl enamines. The reaction was conducted on $0.2 \mathrm{mmol}$ of acyl enamine and $0.4 \mathrm{mmol}$ of alkyl iodide (2.0 equiv.) under indicated conditions.

alcohols could be obtained via hydrolysis without erosion of enantioselectivities ${ }^{53,54}$, which further enhanced the synthetic utility of this method.

Mechanistic consideration. Then, we carried out the reaction using deuterated silane $\left(\mathrm{Ph}_{2} \mathrm{SiD}_{2}\right)^{32}$ under otherwise identical to standard conditions (Fig. 6). The reaction of terminal acyl enamine with 3-phenyl-1-iodopropane in the presence of $\mathrm{Ph}_{2} \mathrm{SiD}_{2}$ afforded deuterated hydroalkylation product 7 in $61 \%$ yield with $93 \%$ ee (Fig. 6a). Only one deuterium incorporation $(>95 \% \mathrm{D})$ was exclusively delivered to $\beta$-position to nitrogen of amide 7 . No deuterium incorporation was found at $\alpha$-position to nitrogen of 7. Next, the reactions of internal acyl enamine of both configurations were tested (Fig. 6b). The reaction of $(E)$-acyl enamine was slightly slower and delivered a lower yield and higher enantioselectivity of $\mathbf{9}$ in comparison to the generation of $\mathbf{8}$ from $(Z)$-acyl enamine ${ }^{50,51}$. These results indicated that $\mathrm{Ni}-\mathrm{H}$ insertion onto acyl enamines to form alkyl-Ni species might be irreversible and enantio-determining.

Based on the mechanistic results and literature precedence $28-34,42-45,48,49$, two tentative mechanistic pathways are proposed and depicted in Fig. 7. In one possibility (Fig. 7a), nickel hydride species could be generated from ligated $\mathrm{Ni}(\mathrm{I})$ precursor in the presence of a silane and a base. $\mathrm{Ni}-\mathrm{H}$ would coordinate with acyl enamines or enol esters (1) to give M1, which could undergo regio- and enantioselective hydrometalation to generate alkyl nickel intermediate M2. This $\mathbf{M} 2$ could oxidize an alkyl iodide (2) to form $\mathrm{Ni}$ (III) intermediate $\mathbf{M} 3$, which could undergo reductive elimination to give the final product 3 and regenerate $\mathrm{Ni}(\mathrm{I})$ catalyst. In the other possibility (Fig. $7 \mathrm{~b}$ ), ligated $\mathrm{Ni}(\mathrm{I})$ precursor undergoes single electron transfer with an alkyl iodide (2) to give an alkyl radical and $\mathrm{Ni}(\mathrm{II})$ intermediate. The latter could generate $\mathrm{Ni}(\mathrm{II})-\mathrm{H}$ in the presence of a silane and a base, which could coordinate with 1 with the assistance of carbonyl group to form $\mathbf{M 1}^{\prime}$. With regio- and enantioselective hydrometalation, $\mathbf{M} 1^{\prime}$ generates alkyl nickel intermediate $\mathbf{M} 2^{\prime}$, which could rebound with the alkyl radical to form $\mathrm{Ni}(\mathrm{III})$ intermediate $\mathbf{M 3}^{\prime}$. M3' undergoes reductive elimination to deliver the final product 3 and regenerate $\mathrm{Ni}(\mathrm{I})$ species.

\section{Discussion}

In summary, a unified protocol for Ni-catalyzed hydroalkylation of acyl enamines and enol esters with alkyl iodides under mild conditions was developed. The use of chiral BOX-based ligand enables the direct access of chiral secondary alkyl-substituted amine and alcohol derivatives in good yields with excellent levels of enantioselectivity, providing a straightforward alternative to pure aliphatic amine and alcohol derivatives which are traditionally challenging to access.

\section{Methods}

General procedure for hydroalkylation of tertiary acyl enamines. In a nitrogenfilled glovebox, $\mathrm{Ni}(\mathrm{COD})_{2}(5.5 \mathrm{mg}, 0.02 \mathrm{mmol}, 10 \mathrm{~mol} \%)$ and $\mathbf{L} \mathbf{9}(21.8 \mathrm{mg}, 0.024$ mmol, $12 \mathrm{~mol} \%)$ were dissolved in solvent $\left(2 \mathrm{~mL}, \mathrm{Et}_{2} \mathrm{O}: \mathrm{DMF}=3: 1\right)$ in a Schlenk tube with screw-cap equipped with a magnetic stirrer. The mixture was stirred at room temperature for $10 \mathrm{~min}$, then alkyl halide $(0.4 \mathrm{mmol})$, tertiary acyl enamine $(0.2$ $\mathrm{mmol})$, and $\mathrm{K}_{3} \mathrm{PO}_{4} \cdot \mathrm{H}_{2} \mathrm{O}(0.6 \mathrm{mmol})$ were added sequentially. The mixture was cooled to $0^{\circ} \mathrm{C}$ before DMMS ( $74 \mu \mathrm{L}, 0.6 \mathrm{mmol}, 3$ equiv.) was added dropwise. The resulting mixture was stirred at $0{ }^{\circ} \mathrm{C}$ for $12-24 \mathrm{~h}$ (for $\mathbf{3 o}-\mathbf{s}$, stirred at $45^{\circ} \mathrm{C}$ ). After completion of the reaction, the mixture was filtered through a pad of silica gel and washed with ethyl acetate $(3 \times 15 \mathrm{~mL})$. The filtrate was washed with water $(15 \mathrm{~mL})$. The organic phase was dried over $\mathrm{Na}_{2} \mathrm{SO}_{4}$, filtered, concentrated under reduced pressure, purified by flash chromatography with silica gel to give the pure product. 


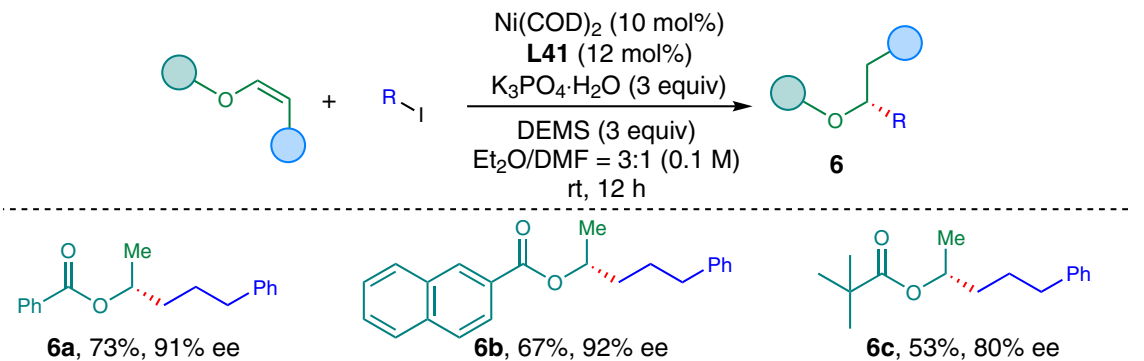<smiles>CCOC(=O)CCC[C@H](C)OC(=O)c1ccccc1</smiles>

6d, $68 \%, 93 \%$ ee<smiles>C[C@H](CCCN1C(=O)c2ccccc2C1=O)OC(=O)c1ccccc1</smiles>

$6 g, 51 \%, 95 \%$ ee<smiles>COCCCC[C@H](C)OC(=O)c1ccccc1</smiles>

$6 e, 65 \%, 93 \%$ ee<smiles>CCCC(=O)OC(C)CCCc1cccs1</smiles>

6f, $80 \%, 90 \%$ ee<smiles>CCCCCC[C@H](C)OC(=O)c1ccccc1</smiles>

6h, $77 \%, 90 \%$ ee<smiles>CCCC[C@H](C)OC(=O)c1ccccc1</smiles>

6i, 54\%, 96\% ee<smiles>C[C@H](OC(=O)c1ccccc1)C1COC1</smiles>

6j, 37\%, 97\% ee e $^{\text {b }}$<smiles>O=C(O[C@H](CCCc1ccccc1)c1ccccc1)c1ccccc1</smiles>

6k, $70 \%, 92 \%$ ee $^{\mathrm{c}}$ trace ${ }^{c}$, from $E$-enol ester<smiles>COc1ccc(C(=O)O[C@@H](CCCCCCO[GeH3])CCCn2c3ccccc3c3ccccc32)cc1</smiles><smiles>CCCCC(OC(=O)c1ccccc1)[C@H](CCCn1c2ccccc2c2ccccc21)OCc1ccccc1</smiles>

$6 \mathrm{~m}, 58 \%, 94 \% \mathrm{ee}^{\mathrm{c}}$ (from Z-enol ester)<smiles>O=C(O[C@H](CCCCCCl)CCCn1c2ccccc2c2ccccc21)c1ccccc1</smiles>

6n, $68 \%, 94 \%$ ee $^{\mathrm{d}}$ (from Z-enol ester)

Fig. 5 Scope for the hydroalkylation of enol esters. The reaction was conducted on $0.2 \mathrm{mmol}$ of enol ester (1.0 equiv.) and alkyl iodide (2.0 equiv.) using potassium phosphate monohydrate (3.0 equiv.) as base in $\mathrm{Et}_{2} \mathrm{O} / \mathrm{DMF}=3: 1(0.1 \mathrm{M})$ at room temperature for $12 \mathrm{~h}$ unless otherwise stated. a5.0 equiv. of $\mathrm{RI}$

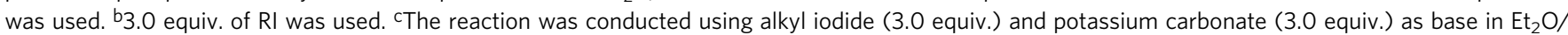
$\mathrm{NMP}=3: 1(0.2 \mathrm{M})$ at $45^{\circ} \mathrm{C}$ for $16 \mathrm{~h}$. ${ }^{\mathrm{d}}$ The reaction was conducted using alkyl iodide (3.0 equiv.) and potassium carbonate (3.0 equiv.) as base in the presence of tert-butanol (4.0 equiv.) in $\mathrm{Et}_{2} \mathrm{O} / \mathrm{NMP}=3: 1(0.2 \mathrm{M})$ at $45^{\circ} \mathrm{C}$ for $16 \mathrm{~h}$. $\mathrm{NMP}=\mathrm{N}$-methyl pyrrolidone.

a Hydroalkylation of terminal acyl enamine with $\mathrm{Ph}_{2} \mathrm{SiD}_{2}$

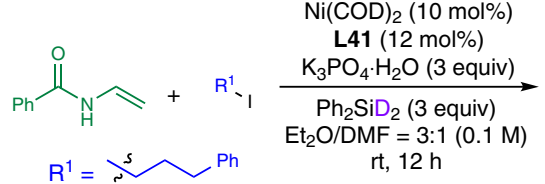

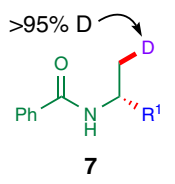

b Hydroalkylation of internal acyl enamine with $\mathrm{Ph}_{2} \mathrm{SiD}_{2}$<smiles>[R][I-]C=CN1CCCC1=O</smiles>

(E) $\mathrm{Ni}(\mathrm{COD})_{2}(10 \mathrm{~mol} \%)$ L9 (12 mol\%) $\mathrm{K}_{3} \mathrm{PO}_{4} \cdot \mathrm{H}_{2} \mathrm{O}$ (3 equiv) $\mathrm{Ph}_{2} \mathrm{SiD}_{2}$ (3 equiv) $\mathrm{Et}_{2} \mathrm{O} / \mathrm{DMF}(3: 1)(0.1 \mathrm{M})$ $45^{\circ} \mathrm{C}, 16 \mathrm{~h}$ $82 \%$ conv.

$\mathrm{Ni}(\mathrm{COD})_{2}(10 \mathrm{~mol} \%)$ L9 (12 mol\%) $\mathrm{K}_{3} \mathrm{PO}_{4} \cdot \mathrm{H}_{2} \mathrm{O}$ (3 equiv) $\mathrm{Ph}_{2} \mathrm{SiD}_{2}$ (3 equiv) $\mathrm{Et}_{2} \mathrm{O} / \mathrm{DMF}(3: 1)(0.1$
$45^{\circ} \mathrm{C}, 16 \mathrm{~h}$ $46 \%$ conv.

\section{General procedure for hydroalkylation of secondary acyl enamines. In a} nitrogen-filled glovebox, $\mathrm{Ni}(\mathrm{COD})_{2}(5.5 \mathrm{mg}, 0.02 \mathrm{mmol}, 10 \mathrm{~mol} \%)$ and $\mathbf{L 4 1}(8.4 \mathrm{mg}$, $0.024 \mathrm{mmol}, 12 \mathrm{~mol} \%)$ were dissolved in solvent $\left(2 \mathrm{~mL}, \mathrm{Et}_{2} \mathrm{O}: \mathrm{DMF}=3: 1\right)$ in a Schlenk tube with screw-cap equipped with a magnetic stirrer. The mixture was stirred at room temperature for $10 \mathrm{~min}$, then alkyl halide $(0.4 \mathrm{mmol})$, acyl enamine $(0.2 \mathrm{mmol})$, and $\mathrm{K}_{3} \mathrm{PO}_{4} \cdot \mathrm{H}_{2} \mathrm{O}(0.6 \mathrm{mmol})$ were added sequentially. The mixture was stirred at room temperature for another $5 \mathrm{~min}$ before DEMS $(98 \mu \mathrm{L}, 0.6 \mathrm{mmol}, 3$ equiv.) was added dropwise. The resulting mixture was stirred at room temperature for $12-24 \mathrm{~h}$. After completion of the reaction, the mixture was filtered through a pad of silica gel and washed with ethyl acetate $(3 \times 15 \mathrm{~mL})$. The filtrate was washed with water $(15 \mathrm{~mL})$. The organic phase was dried over $\mathrm{Na}_{2} \mathrm{SO}_{4}$, filtered, concentrated under reduced pressure, purified by flash chromatography with silica gel to give the pure product.

General procedure for hydroalkylation of enol esters. In a nitrogen-filled glovebox, $\mathrm{Ni}(\mathrm{COD})_{2}(5.5 \mathrm{mg}, 0.02 \mathrm{mmol}, 10 \mathrm{~mol} \%)$ and L41 (8.4 mg, $0.024 \mathrm{mmol}, 12$ mol\%) were dissolved in solvent $\left(2 \mathrm{~mL}, \mathrm{Et}_{2} \mathrm{O}: \mathrm{DMF}=3: 1\right)$ in a Schlenk tube with screw-cap equipped with a magnetic stirrer. The mixture was stirred at room temperature for $10 \mathrm{~min}$, then alkyl halide $(0.4 \mathrm{mmol})$ was added and the mixture was stirred for another $5 \mathrm{~min}$, followed by the sequential addition of enol esters $(0.2 \mathrm{mmol})$ and $\mathrm{K}_{3} \mathrm{PO}_{4} \cdot \mathrm{H}_{2} \mathrm{O}(0.6 \mathrm{mmol})$. The mixture was stirred at room temperature for $5 \mathrm{~min}$ before DEMS $(98 \mu \mathrm{L}, 0.6 \mathrm{mmol})$ was added dropwise. The resulting mixture was stirred at room temperature for 16-20 h. After completion of the reaction, the mixture was filtered through a pad of silica gel and washed with ethyl acetate $(3 \times 15 \mathrm{~mL})$. The filtrate was washed with water $(15 \mathrm{~mL})$. The organic phase was dried over $\mathrm{Na}_{2} \mathrm{SO}_{4}$, filtered, concentrated under reduced pressure, and purified by flash chromatography with silica gel to give the pure product.

\section{Data availability}

The authors declare that all other data supporting the findings of this study are available within the article and Supplementary information files, and also are available from the

Fig. 6 Mechanistic probe for the reaction. a Hydroalkylation of terminal acyl enamine with $\mathrm{Ph}_{2} \mathrm{SiD}_{2}$. $\mathbf{b}$ Hydroalkylation of internal acyl enamine with $\mathrm{Ph}_{2} \mathrm{SiD}_{2}$. 
a Ni (I)-H pathway:
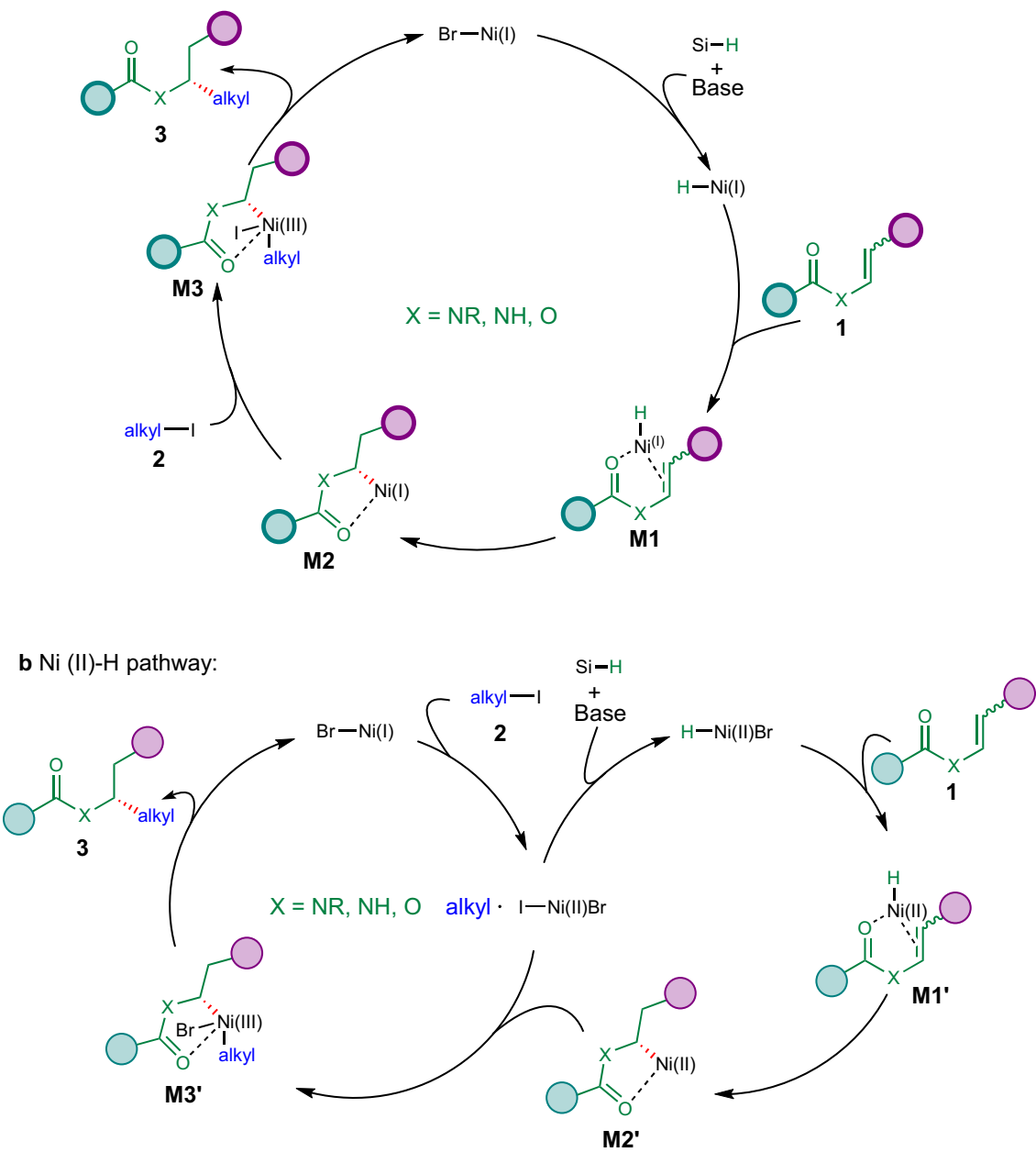

Fig. 7 Proposed mechanism for the reaction. Ligand is omitted for clarity. a $\mathrm{Ni}(\mathrm{I})-\mathrm{H}$ pathway. b $\mathrm{Ni}(\mathrm{II})-\mathrm{H}$ pathway.

corresponding author upon reasonable request. The X-ray crystallographic coordinates for structures reported in this study have been deposited at the Cambridge Crystallographic Data Centre (CCDC), under deposition numbers of CCDC 2042842 and CCDC 2042844. These data can be obtained free of charge from The Cambridge Crystallographic Data Centre via www.ccdc.cam.ac.uk/data_request/cif.

Received: 15 December 2020; Accepted: 9 April 2021;

Published online: 13 May 2021

\section{References}

1. Nugent, T. C. \& El-Shazly, M. Chiral amine synthesis - recent developments and trends for enamide reduction, reductive amination, and imine reduction. Adv. Synth. Catal. 352, 753-819 (2010).

2. Kittakoop, P., Mahidol, C. \& Ruchirawat, S. Alkaloids as important scaffolds in therapeutic drugs for the treatments of cancer, tuberculosis, and smoking cessation. Curr. Top. Med. Chem. 14, 239-252 (2014).

3. Trowbridge, A., Walton, S. M. \& Gaunt, M. J. New strategies for the transition-metal catalyzed synthesis of aliphatic amines. Chem. Rev. 120, 2613-2692 (2020).

4. McGrath, N. A., Brichacek, M. \& Njardarson, J. T. A graphical journey of innovative organic architectures that have improved our lives. J. Chem. Educ. 87, 1348-1349 (2010).

5. Davies, H. M. L. \& Manning, J. R. Catalytic C-H functionalization by metal carbenoid and nitrenoid insertion. Nature 451, 417-424 (2008).

6. Park, Y., Kim, Y. \& Chang, S. Transition metal-catalyzed C-H amination: scope, mechanism, and applications. Chem. Rev. 117, 9247-9301 (2017).

7. Jia, Z.-J., Gao, S. \& Arnold, F. H. Enzymatic primary amination of benzylic and allylic C(sp3)-H bonds. J. Am. Chem. Soc. 142, 10279-10283 (2020).
8. Nakafuku, K. M. et al. Enantioselective radical C-H amination for the synthesis of $\beta$-amino alcohols. Nat. Chem. 12, 697-704 (2020).

9. Liu, G. C., Cogan, D. A. \& Ellman, J. A. Catalytic asymmetric synthesis of tertbutanesulfinamide. Application to the asymmetric synthesis of amines. J. Am Chem. Soc. 119, 9913-9914 (1997).

10. Fujihara, H., Nagai, K. \& Tomioka, K. Copper-amidophosphine catalyst in asymmetric addition of organozinc to imines. J. Am. Chem. Soc. 122, 12055-12056 (2020).

11. Boezio, A. A. \& Charette, A. B. Catalytic enantioselective addition of dialkylzinc to N-diphenylphosphinoylimines. A practical synthesis of $\alpha$-chiral amines. J. Am. Chem. Soc. 125, 1692-1693 (2003).

12. Veguillas, M., Solà, R., Shaw, L. \& Maciá, B. Catalytic asymmetric addition of organolithium reagents to aldehydes. Eur. J. Org. Chem. 2016, 1788-1794 (2016).

13. Fernández-Mateos, E., Maciá, B. \& Yus, M. Catalytic enantioselective addition of alkyl grignard reagents to aliphatic aldehydes. Adv. Synth. Catal. 355 , 1249-1254 (2013)

14. Friedfeld, M. R., Zhong, H., Ruck, R. T., Shevlin, M. \& Chirik, P. J. Cobaltcatalyzed asymmetric hydrogenation of enamides enabled by single-electron reduction. Science 360, 888-893 (2018).

15. Massaro, L., Zheng, J., Margarita, C. \& Andersson, P. G. Enantioconvergent and enantiodivergent catalytic hydrogenation of isomeric olefins. Chem. Soc Rev. 49, 2504-2522 (2020).

16. Jiang, Q., Jiang, Y., Xiao, D., Cao, P. \& Zhang, X. Highly enantioselective hydrogenation of simple ketones catalyzed by a Rh-PennPhos complex. Angew. Chem. Int. Ed. 37, 1101-1103 (1998).

17. Ohkuma, T. et al. Asymmetric hydrogenation of tert-alkyl ketones. J. Am. Chem. Soc. 127, 8288-8289 (2005).

18. Yamamura, T., Nakatsuka, H., Tanaka, S. \& Kitamura, M. Asymmetric hydrogenation of tert-alkyl ketones: DMSO effect in unification of stereoisomeric ruthenium complexes. Angew. Chem. Int. Ed. 52, 9313-9315 (2013). 
19. Garbe, M. et al. Manganese(I)-catalyzed enantioselective hydrogenation of ketones using a defined chiral PNP pincer ligand. Angew. Chem. Int. Ed. 56, 11237-11241 (2017).

20. Štefane, B. \& Požgan, F. Advances in catalyst systems for the asymmetric hydrogenation and transfer hydrogenation of ketones. Catal. Rev. 56, 82-174 (2014).

21. Kobayashi, S., Mori, Y., Fossey, J. S. \& Salter, M. M. Catalytic enantioselective formation of $\mathrm{C}-\mathrm{C}$ bonds by addition to imines and hydrazones: a ten-year update. Chem. Rev. 111, 2626-2704 (2011)

22. Miyabe, H., Ushiro, C., Ueda, M., Yamakawa, K. \& Naito, T. Asymmetric synthesis of $\alpha$-amino acids based on carbon radical addition to glyoxylic oxime ether. J. Org. Chem. 65, 176-185 (2000).

23. Friestad, G. K., Shen, Y. \& Ruggles, E. L. Enantioselective radical addition to $\mathrm{N}$-acyl hydrazones mediated by chiral lewis acids. Angew. Chem. Int. Ed. 42, 5061-5063 (2003).

24. Cho, D. H. \& Jang, D. O. Enantioselective radical addition reactions to the $\mathrm{C}-\mathrm{N}$ bond utilizing chiral quaternary ammonium salts of hypophosphorous acid in aqueous media. Chem. Commun. 2006, 5045-5047 (2006).

25. Zhang, F.-H., Zhang, F.-J., Li, M.-L., Xie, J.-H. \& Zhou, Q.-L. Enantioselective hydrogenation of dialkyl ketones. Nat. Catal. 3, 621-627 (2020).

26. Pirnot, M. T., Wang, Y.-M. \& Buchwald, S. L. Copper hydride catalyzed hydroamination of alkenes and alkynes. Angew. Chem. Int. Ed. 55, 48-57 (2016).

27. Liu, R. Y. \& Buchwald, S. L. CuH-catalyzed olefin functionalization: from hydroamination to carbonyl addition. Acc. Chem. Res. 53, 1229-1243 (2020).

28. Lu, X. et al. Practical carbon-carbon bond formation from olefins through nickel-catalyzed reductive olefin hydrocarbonation. Nat. Commun. 7, 11129 (2016).

29. Lu, X., Xiao, B., Liu, L. \& Fu, Y. Formation of $\mathrm{C}\left(\mathrm{sp}^{3}\right)-\mathrm{C}\left(\mathrm{sp}^{3}\right)$ bonds through nickel-catalyzed decarboxylative olefin hydroalkylation reactions. Chem. Eur. J. 22, 11161-11164 (2016).

30. Zhou, F., Zhu, J., Zhang, Y. \& Zhu, S. NiH-catalyzed reductive relay hydroalkylation: a strategy for the remote $\mathrm{C}\left(\mathrm{sp}^{3}\right)$ - $\mathrm{H}$ alkylation of alkenes. Angew. Chem. Int. Ed. 57, 4058-4062 (2018).

31. Sun, S.-Z., Börjesson, M., Martin-Montero, R. \& Martin, R. Site-selective Nicatalyzed reductive coupling of $\alpha$-haloboranes with unactivated olefins. J. Am. Chem. Soc. 140, 12765-12769 (2018).

32. Bera, S. \& Hu, X. Nickel-catalyzed regioselective hydroalkylation and hydroarylation of alkenyl boronic esters. Angew. Chem. Int. Ed. 58, 13854-13859 (2019).

33. Sun, S.-Z., Romano, C. \& Martin, R. Site-selective catalytic deaminative alkylation of unactivated olefins. J. Am. Chem. Soc. 141, 16197-16201 (2019).

34. Qian, D. \& Hu, X. Ligand-controlled regiodivergent hydroalkylation of pyrrolines. Angew. Chem. Int. Ed. 58, 18519-18523 (2019).

35. Wang, C., Xi, Y., Huang, W., Qu, J. \& Chen, Y. Nickel-catalyzed regioselective hydroarylation of internal enamides. Org. Lett. 22, 9319-9324 (2020).

36. Fu, G. C. Transition-metal catalysis of nucleophilic substitution reactions: a radical alternative to $\mathrm{S}_{\mathrm{N}} 1$ and $\mathrm{S}_{\mathrm{N}} 2$ processes. ACS Cent. Sci. 3, 692-700 (2017).

37. Cherney, A. H., Kadunce, N. T. \& Reisman, S. E. Enantioselective and enantiospecific transition-metal-catalyzed cross-coupling reactions of organometallic reagents to construct C-C bonds. Chem. Rev. 115, 9587-9652 (2015).

38. Cuesta-Galisteo, S., Schörgenhumer, J., Wei, X., Merino, E. \& Nevado, C. Nickel-catalyzed asymmetric synthesis of a-arylbenzamides. Angew. Chem. Int. Ed. 60, 1605-1609 (2021).

39. He, Y., Liu, C., Yu, L. \& Zhu, S. Enantio- and regioselective NiH-catalyzed reductive hydroarylation of vinylarenes with aryl iodides. Angew. Chem. Int. Ed. 59, 21530-21534 (2020).

40. He, Y., Song, H. \& Zhu, S. NiH-catalyzed asymmetric hydroarylation of Nacyl enamines: practical access to chiral benzylamines. Nat. Commun. 12, 638 (2021).

41. Liu, J., Gong, H. \& Zhu, S. Nickel-catalyzed, regio- and enantioselective benzylic alkenylation of olefins with alkenyl bromide. Angew. Chem. Int. Ed. 60, 4060-4064 (2021).

42. Wang, Z., Yin, H. \& Fu, G. C. Catalytic enantioconvergent coupling of secondary and tertiary electrophiles with olefins. Nature 563, 379-383 (2018).

43. Zhou, F., Zhang, Y., Xu, X. \& Zhu, S. NiH-catalyzed remote asymmetric hydroalkylation of alkenes with racemic $\alpha$-bromo amides. Angew. Chem. Int. Ed. 58, 1754-1758 (2019).

44. He, S.-J. et al. Nickel-catalyzed enantioconvergent reductive hydroalkylation of olefins with $\alpha$-heteroatom phosphorus or sulfur alkyl electrophiles. J. Am. Chem. Soc. 142, 214-221 (2020).

45. Yang, Z.-P. \& Fu, G. C. Convergent catalytic asymmetric synthesis of esters of chiral dialkyl carbinols. J. Am. Chem. Soc. 142, 5870-5875 (2020).

46. Sommer, H., Juliá-Hernández, F., Martin, R. \& Marek, I. Walking metals for remote functionalization. ACS Cent. Sci. 4, 153-165 (2018).
47. Vasseur, A., Bruffaerts, J. \& Marek, I. Remote functionalization through alkene isomerization. Nat. Chem. 8, 209-219 (2016)

48. Shi, L., Xing, L.-L., Hu, W.-B. \& Shu, W. Regio- and enantioselective Nicatalyzed formal hydroalkylation, hydrobenzylation, and hydropropargylation of acrylamides to $\alpha$-tertiary amides. Angew. Chem. Int. Ed. 60, 1599-1604 (2021).

49. Bera, S., Mao, R. \& Hu, X. Enantioselective $\mathrm{C}\left(\mathrm{sp}^{3}\right)-\mathrm{C}\left(\mathrm{sp}^{3}\right)$ cross-coupling of non-activated alkyl electrophiles via nickel hydride catalysis. Nat. Chem. 13, 270-277 (2021)

50. Wang, J.-W. et al. Catalytic asymmetric reductive hydroalkylation of enamides and enecarbamates to chiral aliphatic amines. Nat. Commun. 12, 1313 (2021).

51. Qian, D., Bera, S. \& Hu, X. Chiral alkyl amine synthesis via catalytic enantioselective hydroalkylation of enecarbamates. J. Am. Chem. Soc. 143 1959-1967 (2021).

52. Wang, S. et al. Enantioselective access to dialkyl amines and alcohols via Nicatalyzed reductive hydroalkylations. Preprint at https://doi.org/10.26434/ chemrxiv.13284416.v1 (2020)

53. Matteson, D. S., Ray, R., Rocks, R. R. \& Tsai, D. J. S. Directed chiral synthesis by way of $\alpha$-chloro boronic esters. Organometallics 2, 1536-1543 (1983).

54. Wei, X., Shu, W., García-Domínguez, A., Merino, E. \& Nevado, C. Asymmetric Ni-catalyzed radical relayed reductive coupling. J. Am. Chem. Soc. 142, 13515-13522 (2020)

55. Kleman, P., Gonzlez-Liste, P. J., Garca-Garrido, S. E., Cadierno, V., \& Pizzano, A. Highly enantioselective hydrogenation of 1-alkylvinyl benzoates: a simple, nonenzymatic access to chiral 2-alkanols. Chem. Eur. J. 19, 16209-16212 (2013).

\section{Acknowledgements}

Financial support from NSFC (21971101 and 21801126), Guangdong Basic and Applied Basic Research Foundation (2019A1515011976), Thousand Talents Program for Young Scholars, The Pearl River Talent Recruitment Program (2019QN01Y261), and Guangdong Provincial Key Laboratory of Catalysis (No. 2020B121201002) is sincerely acknowledged. We acknowledge the assistance of SUSTech Core Research Facilities. We thank Dr. Xiaoyong Chang (SUSTech) for X-ray crystallographic analysis of $\mathbf{4 1}$ (CCDC 2042844) and 5a (CCDC 2042842).

\section{Author contributions}

S.W. discovered and developed the reaction. W.S. conceived and directed the project. S W., J.X.Z., T.Y.Z., H.M., and B.H.C. performed the experiments and collected the data W.S. wrote the manuscript with contributions from all authors.

\section{Competing interests}

The authors declare no competing interests.

\section{Additional information}

Supplementary information The online version contains supplementary material available at https://doi.org/10.1038/s41467-021-22983-7.

Correspondence and requests for materials should be addressed to W.S.

Peer review information Nature Communications thanks the anonymous reviewer(s) for their contribution to the peer review of this work.

Reprints and permission information is available at http://www.nature.com/reprints

Publisher's note Springer Nature remains neutral with regard to jurisdictional claims in published maps and institutional affiliations.

(i)

Open Access This article is licensed under a Creative Commons Attribution 4.0 International License, which permits use, sharing, adaptation, distribution and reproduction in any medium or format, as long as you give appropriate credit to the original author(s) and the source, provide a link to the Creative Commons license, and indicate if changes were made. The images or other third party material in this article are included in the article's Creative Commons license, unless indicated otherwise in a credit line to the material. If material is not included in the article's Creative Commons license and your intended use is not permitted by statutory regulation or exceeds the permitted use, you will need to obtain permission directly from the copyright holder. To view a copy of this license, visit http://creativecommons.org/ licenses/by/4.0/.

(C) The Author(s) 2021 